2 degrees of warming, with just $10-30 \%$ of existing reefs surviving at $1.5^{\circ} \mathrm{C}$.

Without aggressive action, the world could become an almost impossible place for most people to live in, says Ove Hoegh-Guldberg, director of the Global Change Institute at the University of Queensland in St Lucia, Australia. "As we go toward the end of the century, we have to get this right."

\section{IMPOSSIBLE DREAM}

Given that current national commitments on greenhouse-gas emissions fall well short of the goals laid out in the Paris climate agreement, many scientists have argued that meeting even the $2{ }^{\circ} \mathrm{C}$ goal is almost impossible. But the IPCC report sidestepped questions of feasibility and focused instead on determining what governments, businesses and individuals would need to do to meet the $1.5^{\circ} \mathrm{C}$ goal.

Measures include ramping up the installation of renewable-energy systems, such as wind and solar power, to provide $70-85 \%$ of the world's electricity by 2050 , and expanding forests to increase their capacity to pull carbon dioxide from the atmosphere.

Most scenarios in the report suggest that the world would still need to extract massive amounts of carbon from the atmosphere

and pump it underground in the latter half of this century. The technology to do this is in the early stages of development, and many researchers say that it could be difficult to develop it for use on a global scale.

Other proposed options involve changing lifestyles: eating less meat, riding bicycles more and flying less. The report also waded

\section{Without} aggressive action, the world could become an almost impossible place for most people to live in. into murky questions about ethics and values, stressing that governments must address climate change and sustainable development in parallel, or risk exacerbating poverty and inequality.

The IPCC report includes recent research suggesting that the amount of carbon that humanity can emit while limiting warming to $1.5^{\circ} \mathrm{C}$ might be larger than was thought. The previous IPCC assessment, released in 2014, estimated that the world would breach $1.5^{\circ} \mathrm{C}$ by the early 2020 s at the current rate of emissions. The latest report extends that timeline to 2030 or 2040, on the basis of studies that revised the estimate of warming that has already occurred (R. J. Millar et al. Nature Geosci. 10, 741-747; 2017).
"Every extra tonne of carbon that we dump into the atmosphere today is a tonne that will have to be scrubbed out at the end of the century," says Myles Allen, a climate scientist at the University of Oxford, UK, and one of the lead authors of the report.

"I think we need to start a debate about who is going to pay for it, and whether it's right for the fossil-fuel industry and its customers to be enjoying the benefits today and expecting the next generation to pay for cleaning it up," Allen says.

But scientists have only "medium confidence" in the revised carbon budgets, says Thomas Stocker, a climate scientist at the University of Bern. He says that researchers will provide a more comprehensive look at the numbers in the next full climate assessment, which is scheduled to be released in 2021 .

In the meantime, the newer and larger carbon budget could send the wrong message to policymakers, says Oliver Geden, a social scientist and visiting fellow at the Max Planck Institute for Meteorology in Hamburg, Germany. He fears that the IPCC report undersells the difficulty of achieving the $1.5^{\circ} \mathrm{C}$ goal. "It's always five minutes to midnight, and that is highly problematic," he says. "Policymakers get used to it, and they think there's always a way out." -

\title{
Peer-reviewed homeopathy study sparks uproar in Italy
}

\section{Homeopathy advocates have championed the paper, but scientists doubt its claims.}

\section{BY GIORGIA GUGLIELMI}

A study ${ }^{1}$ that claims to show that a homeopathic treatment can ease pain in rats has caused uproar after it was published in a peer-reviewed journal. Groups that promote homeopathy in Italy, where there is currently a debate about how to label homeopathic remedies, have held the study up as evidence that the practice works. But several researchers have cast doubt on its claims.

The authors acknowledge some errors flagged in an analysis of the paper by a separate researcher, but stand by their overall conclusions. One of the authors, pharmacologist Chandragouda Patil of the R. C. Patel Institute of Pharmaceutical Education and Research in Dhule, India, also says that the results are preliminary and cannot yet be applied to people, and that he hopes that the team's findings will encourage other researchers to conduct clinical studies.

Researchers have presented evidence in support of homeopathy before - famously, in a 1988 Nature paper ${ }^{2}$ by French immunologist Jacques Benveniste that was later discredited. This latest claim has attracted attention, in part, because it passed peer review at the journal Scientific Reports. (Nature's news team is editorially independent of its publisher Springer Nature, which also publishes Scientific Reports.)

"It's worrying that a major journal like Scientific Reports didn't pay close attention to a study that claims to show that homeopathy works," says Enrico Bucci, the researcher who carried out the analysis of the paper. Bucci is co-founder of the company Resis in Turin, Italy, which provides tools to uncover potential problems with scholarly articles, and a researcher in systems biology at Temple University in Philadelphia, Pennsylvania.

A paper that claims something as exceptional as the corroboration of homeopathy but also contains errors "raises questions on whether the review process was adequate", adds Michelangelo Cordenonsi, a cancer researcher at the University of Padova in Italy. A spokesperson for Scientific Reports, which published the paper on 10 September, says that the editors are looking into the criticisms, and will correct or retract the paper if necessary. On 1 October, the journal added an editors' note to the homeopathy paper alerting readers to criticisms regarding the study.

\section{HEALING RESPONSE}

Homeopathy is based on the idea that illnesses can be treated using substances that produce similar symptoms. Mostly, the substances have been heavily diluted in water or alcohol so that none or only a few molecules of the active ingredient are present. Some supporters of the practice say that the water or alcohol 'remembers' the substance, which triggers a healing response. But these claims aren't backed up by scientific evidence, and the European Academies' Science Advisory Council notes that homeopathic products are no more effective than placebos in treating health problems. 
- Patil and colleagues report that a homeopathic product (a heavily diluted extract from Toxicodendron pubescens, a plant known as Atlantic poison oak) is as effective as the prescription drug gabapentin in reducing inflammation and pain responses in lab-grown cells and animals.

Homeopathy groups worldwide have welcomed the study. And in Italy, where a proposal to label homeopathic products as 'preparations' rather than 'drugs' has provoked heated debate, homeopaths and their associations have said that the study's publication demonstrates the effectiveness of homeopathy.

On social media and in the press, scientists in Italy have voiced concerns about the study. In his analysis, Bucci used his company's software to detect two identical images that supposedly describe different experiments in one of the paper's figures. He also found in the body of the text that the authors write that they had treated the animals with heavily diluted Toxicodendron pubescens (up to $1 \times 10^{-30}$ ), but the data in one of the figures show the effects for dilutions up to $1 \times 10^{-8}$. These discrepancies, as well as the image duplications, were also flagged by others on PubPeer, a platform to discuss scholarly articles. In another figure, Bucci spotted what seem to be the same data for two different experiments. He published his analysis online on 26 September and sent a detailed report to the editors of Scientific Reports on 3 October.

Patil attributes the duplicated images and the repeated data to mistakes that his team made while preparing the manuscript. The discrepancies between the text and the figures are the result of typos, according to Patil. The group will ask Scientific Reports to update the article with a correction. But "this does not change the scientific conclusions in any way", Patil says. All the experiments were done "with utmost integrity". The aim of the study was neither to criticize nor to support homeopathy, but to evaluate a homeopathic product using "pharmacological principles", he adds.

Bucci says that he has also found that some of the study's authors, including Patil, had written another paper ${ }^{3}$ published in Scientific Reports in 2016 that he says also contains inappropriate image duplications. Patil says that these occurred while converting the figures to high resolution when the researchers submitted the manuscript to the journal. The group will ask Scientific Reports to correct that article too, he says.

The spokesperson for Scientific Reports says that the editors are looking into the issues raised for both papers. "We take our responsibility to maintain the accuracy of the scientific record very seriously." -

1. Magar, S. et al. Sci. Rep. 8, 13562 (2018).

2. Davenas, E. et al. Nature 333, 816-818 (1988).

3. Chanchal, S. K. et al. Sci. Rep. 6, 30007 (2016).

PUBLISHING

\section{Europe's open-access plan seeks US support}

\section{Plan S architect heads to the White House.}

\section{BY HOLLY ELSE}

A month after European funders launched the 'Plan S' initiative, which demands open access to scientific papers immediately after publication by 2020 , the plan's creators have revealed more details and are seeking support from US policymakers.

"We cannot afford to stand still or slow down. By the end of the year, if we don't have more funders and statements of support, we will miss the boat," says Robert-Jan Smits, the European Commission's senior adviser on open access. Smits was in the United States last week to talk to research funders, scientific societies and representatives of the White House's Office of Science and Technology Policy. "I'm going for business, not chitchat," he told Nature.

Smits has also named John-Arne Røttingen, head of the Research Council of Norway, and David Sweeney, executive chair of the funding body Research England, as the leaders of a task force that will decide how funders will implement Plan S. Sweeney accompanied Smits to the United States, along

\section{"We cannot afford to stand still or slow down."}

with Marc Schiltz, president of the Brusselsbased advocacy group Science Europe, which published Plan S on 4 September.

The task force will release more details by the end of this year, and will consider whether publishers might develop new business models that "outsmart" the plan's requirements, Smits says.

Initially, a coalition of 11 national research funders, including agencies in France, the Netherlands and the United Kingdom, backed the plan; on 24 September, the Academy of Finland joined the group. Plan S funders say that, from 2020, they will require scientists who receive grants from them to make the resulting papers free to read immediately on publication, with a liberal publishing licence allowing others to download, translate or otherwise reuse the work. By contrast, the US National Institutes of Health allows up to one year before papers must be made openly available.

The plan, which aims to flip journals to fully open-access publishing, also states that scientists can't publish in 'hybrid' journals, which collect subscriptions but permit some papers to be published openly for a fee. As written, Plan S would bar researchers from publishing in $85 \%$ of journals, including Nature and Science - unless the journals adapt their business models to open-access publishing. (Nature's news team is editorially independent of its publisher, Springer Nature.)

But details remain unclear. Since the plan's launch, for instance, researchers have wondered whether they would be complying with its intentions if they immediately made a copy of their accepted paper available online even if the publisher kept the work paywalled.

In mid-September, Smits suggested at the conference of the Open Access Scholarly Publishers Association in Vienna that this would be consistent with Plan S, as long as the open version used a liberal publishing licence. That might mean that paywalled journals could respect Plan $S$ without changing their publishing models. But it is not clear whether this would apply to hybrid journals. Details such as which licence would be acceptable for the archived manuscript, and whether the publisher or the author would retain copyright, also remain fuzzy.

\section{ACADEMIC FREEDOM}

Since the plan's launch, an argument has also flared up over whether funders should be able to restrict where academics can publish. Britt Holbrook, a philosopher at the New Jersey Institute of Technology in Newark, co-wrote a blogpost arguing that the plan is unethical because regulating where researchers can publish impinges on academic freedom. His co-authors include some European scientists, such as biochemist Lynn Kamerlin at Uppsala University in Sweden.

But other researchers disagree. Peter Suber, director of the Harvard Open Access Project in Cambridge, Massachusetts, says it is reasonable for funders to restrict how their money is used. Suber says that taxpayer-funded research agencies have a duty to spend their money in the public interest.

Smits says it is a "pity" that the academicfreedom argument is being used, "because it stifles a lot of debate". He says it will be key for the task force to think through the potential consequences of Plan S, to mitigate the risk of publishers developing new business models that the coalition "will regret after five years". "We need to think three moves ahead, like a chess game," he says. 